\title{
The effect and underlying mechanism of Timosaponin B-II on RGC-5 necroptosis induced by hydrogen peroxide
}

\author{
San-Hong Jiang ${ }^{1 \dagger}$, Lei Shang ${ }^{1+}$, Li-Xiang Xue ${ }^{2}$, Wei Ding ${ }^{1}$, Shuang Chen ${ }^{1}$, Ruo-Fei Ma ${ }^{3}$, Ju-Fang Huang ${ }^{1 *}$ \\ and Kun Xiong ${ }^{1 *}$
}

\begin{abstract}
Background: Necroptosis is an important mode of cell death, which is due to oxidant stress accumulation. Our previous study indicated that oxidant stresses could be reduced by Timosaponin B-II (TBII), a kind of Chinese herb RhizomaAnemarrhenae monomer extraction. We wonder the possible effect of Timosaponin B-Il, whether it can protect cells from necroptosis via reducing the oxidant stress, in RGC-5 following hydrogen peroxide $\left(\mathrm{H}_{2} \mathrm{O}_{2}\right)$ insult.

Methods: RGC-5 cells were grown in DMEM, the model group was exposed in $\mathrm{H}_{2} \mathrm{O}_{2}$ with the concentration of $300 \mu \mathrm{M}$, and the experimental group was pre-treated with Timosaponin B-Il at different concentrations (1 $\mu \mathrm{M}$, $10 \mu \mathrm{M}, 100 \mu \mathrm{M}$ and $1000 \mu \mathrm{M})$ for $24 \mathrm{hrs}$. MTT assay was carried out to measure the cytotoxicity of $\mathrm{H}_{2} \mathrm{O}_{2}, \mathrm{MDA}$ concentration assay was executed to evaluate the degree of oxidative stress, TNF-a ELISA Assay was used to measure the concentration of TNF-a, finally, the degree of necrosis were analyzed using flow cytometry.
\end{abstract}

Results: We first constructed the cell injury model of necroptosis in $\mathrm{RGC}-5$ upon $\mathrm{H}_{2} \mathrm{O}_{2}$ exposure. Morphological observation and MTT assay were used to evaluate the degree of RGC-5 death. MDA assay were carried out to describe the degree of oxidant stress. Annexin V/PI staining was used to detect necroptotic cells pre-treated with or without Timosaponin B-II following $\mathrm{H}_{2} \mathrm{O}_{2}$ injury. TNF-a ELISA was carried out to detect the TNF-a accumulation in RGC-5. Upon using Timosaponin B-II with concentration of $100 \mu \mathrm{M}$, the percentage of cell viability was increased from $50 \%$ to $75 \%$, and the necrosis of cells was reduced from $35 \%$ to $20 \%$ comparing with $\mathrm{H}_{2} \mathrm{O}_{2}$ injury group. Oxidant stress and TNF-a was reduced upon injury which decreased the ratio of RGC-5 necroptosis.

Conclusion: Our study found out that Timosaponin B-II might reduce necroptosis via inhibition of ROS and TNF-a accumulation in $\mathrm{RGC}-5$ following $\mathrm{H}_{2} \mathrm{O}_{2}$ injury.

Keywords: Retinal ganglion cells-5, Timosaponin B-II, TNF-a, Necroptosis, Oxidative stress

\section{Background}

Necroptosis is a novel kind of cell death which has similar morphological features of necrosis [1,2]. The previous studies pointed out that necroptosis was usually initiated by TNF- $\alpha$ or FasL, etc. and transmitted by certain specific cytokines, which results in the accumulation of oxidative products and eventually leading to necrosis. However, it can be blocked by necrostatin-1 (Nec-1, a

\footnotetext{
* Correspondence: huangjufang@csu.edu.cn; xiongkun2001@163.com ${ }^{\dagger}$ Equal contributors

Department of Anatomy and Neurobiology, School of Basic Medical Science, Central South University, Changsha, Hunan 410013, China Full list of author information is available at the end of the article
}

specific inhibitor of necroptosis) [1]. Necroptosis existed in different cell types, such as epidermal keratinocytes [3], Jurkat T cells [4], L929 cells [5,6], HepG2 cells [7], hippocampal neurons [8], cortical neurons [9] and photoreceptor cells [10], etc. upon injury. Furthermore, Rosenbaum, et al. have found a large number of necrotic cells exist in rat retinal ganglion cell layer by PI staining at the early stage of acute high intra-ocular pressure (aHIOP) [11]. The numbers of PI-positive neuron decreased, and the "b" wave was partially restored in flash ERG with Nec-1 pretreatment. Dvoriantchikova's recent works showed that retinal ganglion cells (RGCs) necroptosis promoted in aHIOP-induced retinal damage [12], 
which has the similar finding with our previous work [13]. Additionally, our recent studies have also indicated that necroptosis occurs in retinal ganglion cells-5 (RGC5 ) at an early stage following elevated hydrostatic pressure (EHP) in vitro [14] or hydrogen peroxide $\left(\mathrm{H}_{2} \mathrm{O}_{2}\right)$ treatment (our unpublished data) detected by flow cytometry (a typical way to monitor necroptosis) [15].

Although some scientists recently have synthesized necroptosis inhibitors, such as Nec-3 [16], Nec-5 [17], Nec-7 [18], Nec-21 [19], etc., the mechanism still needs to be further clarified. Nec-1 is a synthetic small molecular compound which is the most commonly used in necroptosis inhibition [1]. So far, there are no reports about whether it has side effects when it is applied to animal or cellular models. Traditional Chinese herb rhizomaanemarrhenae is the dried rhizome of anemarrhenaasphodeloidesbge. It contains lots of steroidal saponins including sarsasapogenin, markosapogenin, negitogenin, diosgenin and its glycosylated derivatives, like Timosaponin A-I, A-II, A-III, A-IV, B-I, B-II,C, D and Timosaponin $\mathrm{E}$ [20]. Li [21] indicated that Timosaponin B-II (Figure 1, the chemical structure of Timosaponin B-II, CAS number: 136656-07-0) might improve the impairment of learning and memory caused by cerebral ischemia in a dose-dependent manner. Lu [11] and Kim's [22] research suggested that, Timosaponin B-II could not only inhibit the production of IL-1 $\beta$ and IL-6, but also TNF- $\alpha$ (one of important molecules which initiates necroptosis), these results suggested the effect might be related to Timosaponin B-II which has anti-inflammatory activity. Besides, Zhang [23] and Kaname [24] found Timosaponin E-I, E-II, B-II, B-III and A-III played an important role in superoxide dismutase-generation. Deng [25] demonstrated that culturing primary rat neurons (A $\beta_{25-35}$ insult model) with Timosaponin B-II at a certain range of concentrations showed remarkable anti-oxidative damage effects, which indicated Timosaponin B-II could remove oxygen radicals, and keep the intra-cellular redox reactions in a dynamic equilibrium [26]. Our previous study also showed that Timosaponin B-II participated in the protection of rat RGCs which was treated by $\mathrm{FeCl}_{3}$ solution via anti-oxidation [27]. Of note, whether

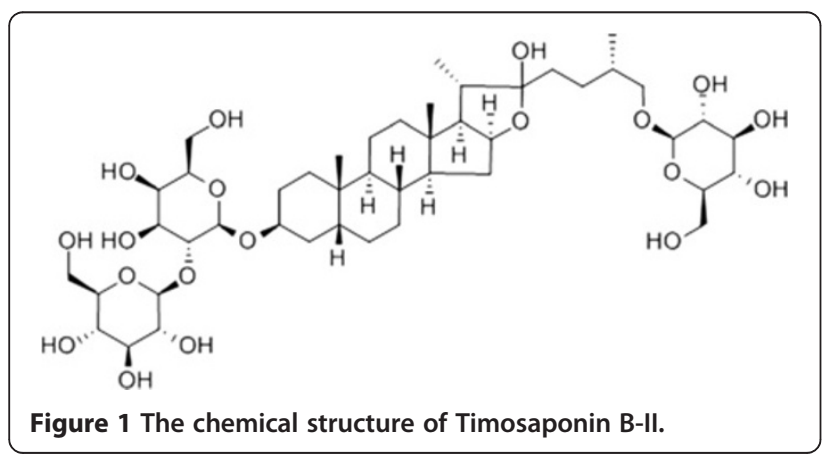

Timosaponin B-II could inhibit oxidative stress-induced RGCs necroptosis or not, it is still under investigation. Therefore, our present experiments focused on Timosaponin B-II's potential roles in RGC-5 necroptosis suppression upon hydrogen peroxide $\left(\mathrm{H}_{2} \mathrm{O}_{2}\right)$ treatment. Meanwhile, the effect of Timosaponin B-II on malondialdehyde (MDA, biomarker of oxidative stress) and TNF- $\alpha$ in RGC-5 has been investigated. Our study may give a better understanding of the protective effect of Timosaponin B-II upon neuronal injury, and provide the experimental basis of novel mechanism on cell death.

\section{Methods}

\section{Cell culture}

The mouse retinal ganglion cell line (RGC-5) was contributed by Department of Ophthalmology, Second Hospital of Ji Lin University, China [28]. RGC-5 cells were grown in Dulbecco's Modified Eagle Medium (DMEM, HyClone Laboratories, Inc. UT, USA) and supplemented with $10 \%$ fetal bovine serum (FBS, HyClone Laboratories, Inc. UT, USA), $100 \mathrm{U} / \mathrm{ml}$ of penicillin and $100 \mu \mathrm{g} / \mathrm{ml}$ of streptomycin (HyClone Laboratories, Inc. UT, USA). The RGC-5 cells used in the experiment were with 2-3 passages post-thawed to minimize the variability in the assays based on our observations. The density of RGC- 5 cells was around $80 \%$ in $6 \mathrm{ml}$ culture media in $50 \mathrm{ml}$ flask before insults $\left(\mathrm{H}_{2} \mathrm{O}_{2}\right.$ treatment).

\section{Reagent}

The powder of Timosaponin B-II was provided by Professor Wan-Sheng Chen from Department of Pharmacology, School of Pharmacology, Second Military Medical University, Shanghai, China $[29,30]$ and its purity is above $98 \%$. Timosaponin B-II was dissolved in sterile normal saline (NS) at $2 \mathrm{mM}$ in room temperature $\left(24^{\circ} \mathrm{C}\right.$ ), $\mathrm{H}_{2} \mathrm{O}_{2}$ (SigmaAldrich, MO, USA) with $0.01 \mathrm{M} \mathrm{PBS}$ at $3 \mathrm{mM}$ in store to yield a low concentration working solutions.

\section{Cell model construction and drug treatment}

Cells were equally divided into three groups randomly. The normal control group (CTL), the model group $\left(\mathrm{H}_{2} \mathrm{O}_{2}\right.$, $300 \mu \mathrm{M})$, and the experimental group $\left(\mathrm{H}_{2} \mathrm{O}_{2}+\right.$ Timosaponin B-II). The experimental group was pre-treated with Timosaponin B-II at different concentrations $(1 \mu \mathrm{M}, 10$ $\mu \mathrm{M}, 100 \mu \mathrm{M}$ and $1000 \mu \mathrm{M})$ for $24 \mathrm{hrs}$. No drugs were exposed to the normal control or the model group. After that, we used $\mathrm{H}_{2} \mathrm{O}_{2}$ of $300 \mu \mathrm{M}$ for 12 hrs to get cell insult and randomly selected three in each group for morphological studies while the remaining cells were used for biochemistry studies. For morphological study, the pictures of the attached cells were captured using inverted microscope in $10 \times$ objective (Olympus, CKX41, Tokyo, Japan). 
We have captured ten pictures at least in each group, and selected the typical graphics to illustrate.

\section{MTT assay}

Cytotoxicity of $\mathrm{H}_{2} \mathrm{O}_{2}$ model group and Timosaponin BII pretreated group $(1 \mu \mathrm{M}, 10 \mu \mathrm{M}, 100 \mu \mathrm{M}$ and 1000 $\mu \mathrm{M})$ were assessed in RGC-5 cells by measuring the amount of insoluble formazan formed in live cells based on the reduction of $3-(4,5$ dimethylthiazol-2-yl)-2, 5-diphenyltetrazolium bromide (MTT) salt (Nanjing Jian-Cheng Bio-engineering Institute, Jiangsu, China) according to the manufacturer's protocol. The cells were seeded in 96-well plates with a density of $10^{4}$ cells/well incubated for $24 \mathrm{hrs}$ at $37^{\circ} \mathrm{C}$ and $5 \% \mathrm{CO}_{2}$. The cells were pretreated with different concentrations of Timosaponin B-II before $\mathrm{H}_{2} \mathrm{O}_{2}$ insult or $\mathrm{H}_{2} \mathrm{O}_{2}$ used alone and PBS as a negative control. Within $24 \mathrm{hrs}$ pre-treatment of Timosaponin B-II, $50 \mu \mathrm{l}$ of MTT labeling reagent $(2 \mu \mathrm{g} /$ $\mathrm{ml})$ was added to each well. The plates were incubated at $37^{\circ} \mathrm{C}$ in a humidified atmosphere with $5 \% \mathrm{CO}_{2}$ for 4 hrs. Thereafter, $100 \mu \mathrm{l}$ of the solubilization solution was added to each well and followed by incubation overnight at $37^{\circ} \mathrm{C}$ to dissolve formazan crystals. Absorbance was ultimately read using an ELISA plate reader (Bio-tek, ELx800, IL, USA) at a wavelength of $570 \mathrm{~nm}$. Where, $\mathrm{H}_{2} \mathrm{O}_{2}$ model group and Timosaponin B-II pretreated group are mean absorbance of treated cells and negative control, respectively.

\section{MDA concentration assay}

MDA levels in RGC-5 extractions were assayed using a commercial kit according to manufacturer's instructions (Nanjing Jian-Cheng Biotechnical Co., Jiangsu, China) as in our previous study [27], the standard reference substance named tetraethoxypropane were used in 10 $\mathrm{nmol} / \mathrm{ml}$. Equal quantities $(100 \mu \mathrm{g})$ of protein were loaded in each well and each analysis performed in duplicate.

\section{TNF- $a$ ELISA assay}

A RGC-5 TNF- $\alpha$ concentration assay was performed using a commercial TNF- $\alpha$ ELISA kit (Invitrogen, CA, USA). The detailed processes were conducted according to the manual included in the kit. Positive control: the antibody tested in the kit was replaced by mouse TNF- $\alpha$ (provided in assay, concentration: $720 \mathrm{ng} / \mathrm{L}$ ). Equal quantities of protein $(80 \mu \mathrm{g})$ were analyzed in every tested well and the measurements were carried out by Bio-tek microplate-reader (ELx800, IL, USA). The percentage of TNF- $\alpha$ concentration in normal control group was set as $100 \%$. All experiments were repeated at least twice.

\section{Flow cytometry}

The cells attached to the flasks were trypsinized followed by a gentle wash. The experimental group was pretreated with Timosaponin B-II at $100 \mu \mathrm{M}$. The model group was treated with $\mathrm{H}_{2} \mathrm{O}_{2}$ at $300 \mu \mathrm{M}$. Resuspended the cells in $200 \mu \mathrm{l}$ of $1 \times$ binding buffer, and then added $5 \mu \mathrm{l}$ of $20 \mu \mathrm{g} / \mathrm{ml}$ Annexin $\mathrm{V}$ and $10 \mu \mathrm{l}$ of $50 \mathrm{mg} / \mathrm{ml} \mathrm{PI}$, incubated at RT for 15 mins in the dark. After the cells were washed and analyzed by FACS Calibur (Becton, Dickinson Company, NJ, USA). The percentages of cells in each quadrant were analyzed using ModFit software (Verity Software House Topsham, NJ, USA). Statistical results of flow cytometry were conducted by calculating the PI+ cells numbers. All the results were repeated three times.

\section{Data analysis}

Figure panels were assembled by using Photoshop CC (Adobe, CA, USA). The data were analyzed by using SPSS 19.0 (SPSS, IL, USA). One-way analysis of variance (one-way ANOVA) was performed to test differences in average value between groups. All results were presented as mean $\pm \mathrm{SD}$. A value of $p<0.05$ was considered statistically significant.

\section{Results}

Timosaponin B-II could protect RGC-5 from $\mathrm{H}_{2} \mathrm{O}_{2}$ injury

The normal RGC-5 cell graphic were shown in Figure $2 \mathrm{~A}$. The cells grew in apposite density and adherent well with axon-elongated and interweave each other to be a mesh, each of them presented as identical size and consistent morphology. The number of the cells decreased in $\mathrm{H}_{2} \mathrm{O}_{2}$ injury group (Figure $2 \mathrm{~B}$ ), and plenty of them were detached and floated in culture media. As shown in Figure C-E, the number of adherent cells increased following the incubated concentration of Timosaponin B-II increase, it is worth noting that the number of adherent cells in $1000 \mu \mathrm{M}$ Timosaponin B-II treatment group is less than those in $100 \mu \mathrm{M}$ Timosaponin B-II treatment group (Figure $\mathrm{E}$ and $\mathrm{F}$ ). These results indicated that Timosaponin B-II could protect RGC-5 from $\mathrm{H}_{2} \mathrm{O}_{2}$ insult yield to the concentration manner, but the effect may reverse with higher concentrations of Timosaponin B-II in $1000 \mu \mathrm{M}$.

\section{Timosaponin B-Il could increase RGC-5 viability upon $\mathrm{H}_{2} \mathrm{O}_{2}$ injury}

In order to evaluate the viability of RGC-5 in model group and Timosaponin B-II treatment group, we carried out MTT assay to detect cell viability. The statistical analysis of MTT result was shown in Figure 3. Comparing to normal control group (CTL), the cell viability was significantly decreased in model group and Timosaponin B-II treatment group. The cell viability kept gradually increasing 

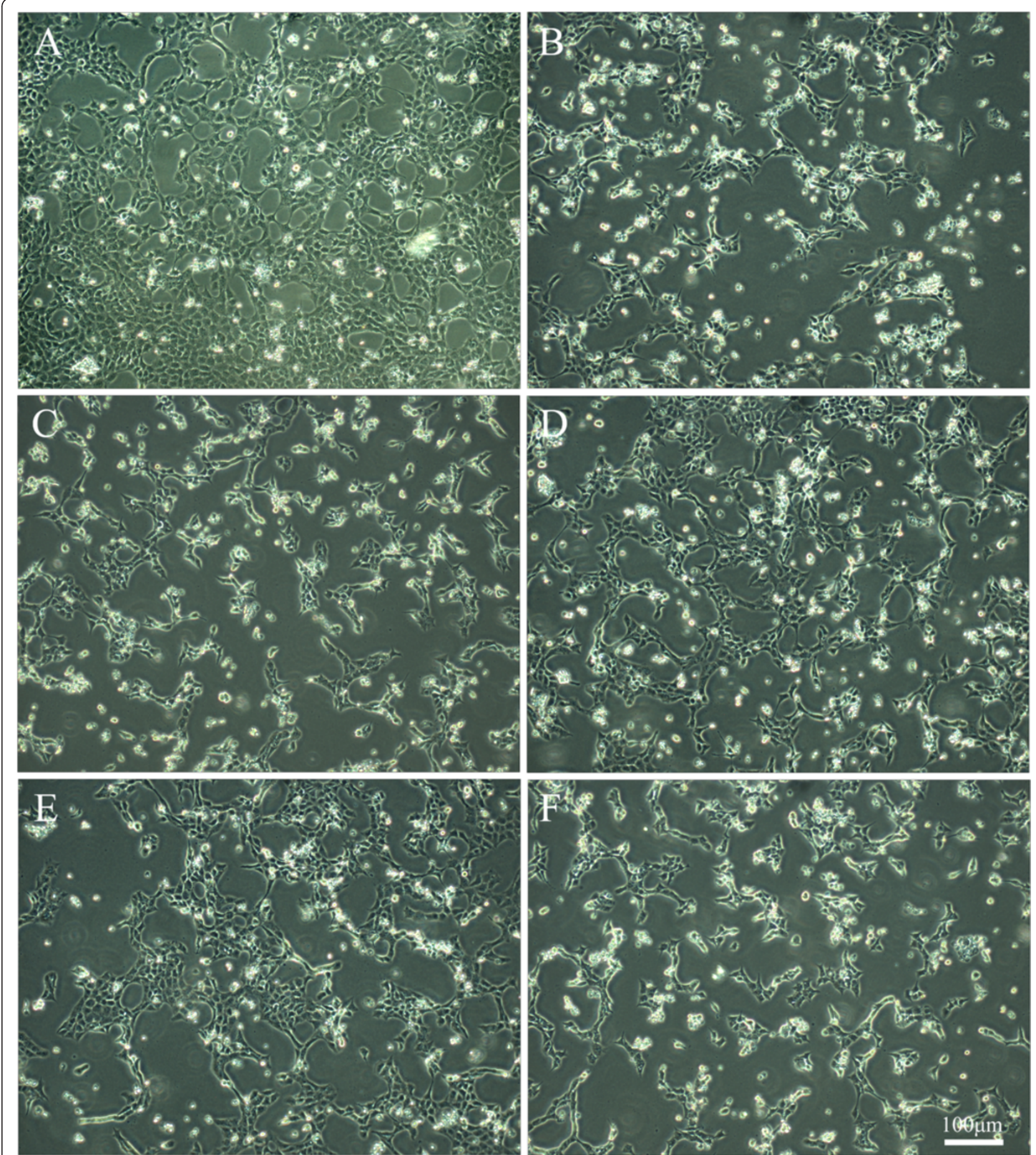

Figure 2 The morphological graphic of RGC-5 cell line insult with $\mathrm{H}_{2} \mathrm{O}_{2}$ after 12 hrs pretreating in different concentration of TBII by inverted microscope; A: Normal Control; B: Model group $\left(\mathrm{H}_{2} \mathrm{O}_{2}\right.$ treatment); C: TBII pretreatment group $\left(\mathrm{H}_{2} \mathrm{O}_{2}+1 \mu \mathrm{M}\right.$ TBII); D: TBII pretreatment group $\left(\mathrm{H}_{2} \mathrm{O}_{2}+10 \mu \mathrm{M}\right.$ TBII); E: TBII pretreatment group $\left(\mathrm{H}_{2} \mathrm{O}_{2}+100 \mu \mathrm{M}\right.$ TBII); F: TBII pretreatment group $\left(\mathrm{H}_{2} \mathrm{O}_{2}+1000\right.$ $\mu \mathrm{M}$ TBII), Scale bar $=100 \mu \mathrm{m}$ in A-E.

upon elevating the concentration of Timosaponin B-II except $1000 \mu \mathrm{M}$ Timosaponin B-II group. These results indicated that Timosaponin B-II could rescue RGC-5 viability, which was impaired by the $\mathrm{H}_{2} \mathrm{O}_{2}$.
Timosaponin B-II reduced MDA production in RGC-5

The statistical analysis of MDA level is shown in Figure 4. The level of MDA in the experimental group (except 1000 $\mu \mathrm{M}$ Timosaponin B-II treatment group) kept decreasing 


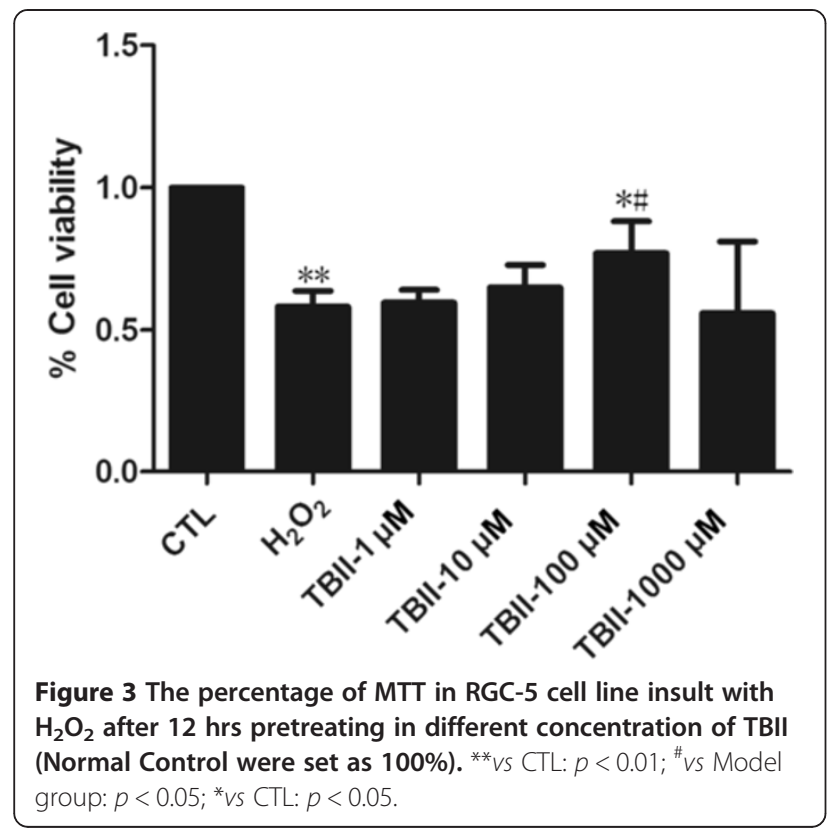

gradually compared to the model group upon $\mathrm{H}_{2} \mathrm{O}_{2}$ insult after increasing the concentration of Timosaponin B-II, but it remained at higher level than those in normal control group (CTL). In $100 \mu \mathrm{M}$ Timosaponin B-II treatment group, the level of MDA decreased significantly compared with $\mathrm{H}_{2} \mathrm{O}_{2}$ insult group $(p<0.05)$. These results indicated that Timosaponin B-II reduced the oxidative stress which is usually induced by $\mathrm{H}_{2} \mathrm{O}_{2}$ in RGC-5. Nevertheless, the capacity of anti-oxidant was limited, because the oxidative stress remained higher than normal control group in Timosaponin B-II treatment group.

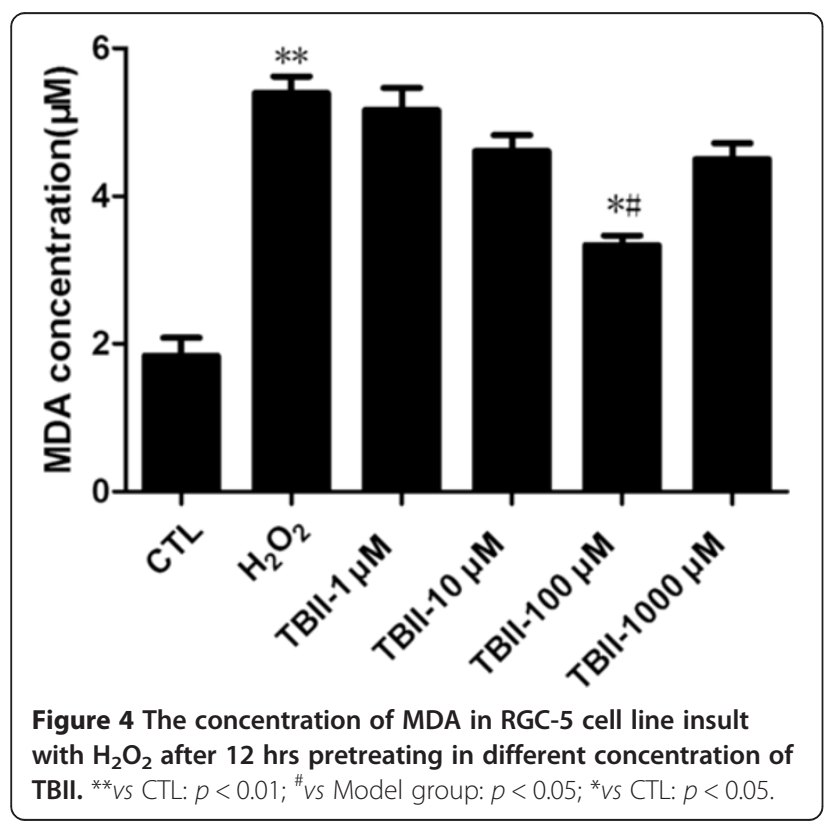

Timosaponin B-II inhibited TNF-a production in RGC-5

The statistical analysis of ELISA assay for TNF- $\alpha$ level was described in Figure 5. The level of TNF- $\alpha$ in the experimental group (except $1000 \mu \mathrm{M}$ Timosaponin B-II treatment) was gradually decreasing compared to the model group after increasing the concentration of Timosaponin B-II, but it remained at higher levels compared to those in normal control group. These results indicated that Timosaponin B-II remarkably inhibited TNF- $\alpha$ production. Nevertheless, the effect of Timosaponin B-II was impaired to a certain extent since the level of target peptides was still higher than those in normal condition.

Timosaponin B-II may decrease the rate of RGC-5 necrosis Upon $300 \mu \mathrm{M} \mathrm{H} \mathrm{H}_{2} \mathrm{O}_{2}$ insult, necrosis in RGC-5 occurred in our study. Therefore, the cells were treated under this condition with the addition of Timosaponin B-II at different concentrations. After that, we analyzed cellular necrosis by using flow cytometry with $\mathrm{PI} /$ Annexin V double staining, and detected whether it could decrease the rate of necrosis in RGC-5 with pretreatment of Timosaponin B-II upon $\mathrm{H}_{2} \mathrm{O}_{2}$ insult. These results showed that the ratio of necrosis cells is $30.3 \%$ (Figure $6 \mathrm{~B}$ ), the percentage decreased to $22.8 \%$ upon adding Timosaponin B-II (100 $\mu \mathrm{M}$, Figure 6C). Meanwhile, statistical analysis indicated that there were significant changes in the rate of PI-positive RGC-5 in Timosaponin B-II pretreatment group compared with normal control group and $\mathrm{H}_{2} \mathrm{O}_{2}$ model group (Figure 6D). These results indicated that RGC-5 necroptosis in the early stage may decrease with Timosaponin B-II usage.

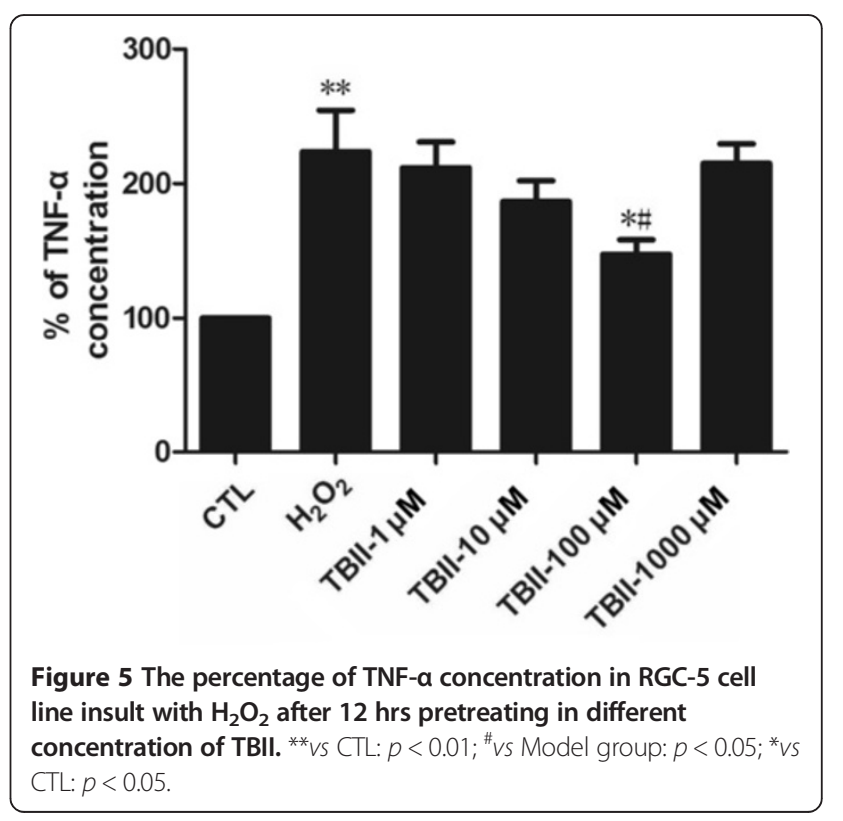




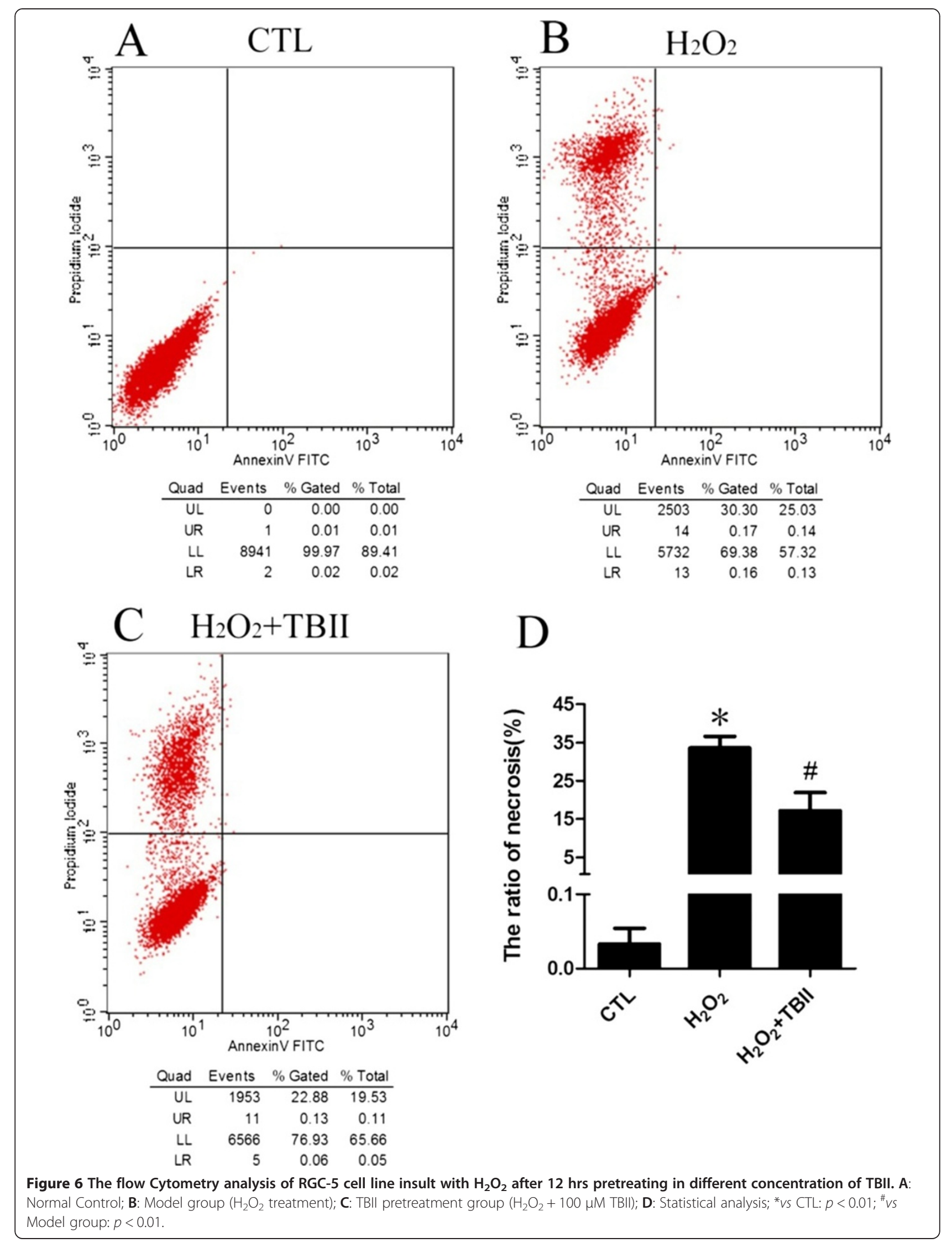




\section{Discussion}

At present, mechanism of cell death is one of the hotspot in the field of life science research. As far as we are concerned, compared to apoptosis and autophagy, the researchers did not pay enough attention to necrosis due to the traditional viewpoint that it cannot be modulated and intervened. Necroptosis is the latest cell death mode which was conceptualized in last century in mid-1980s [31]. Since then, it started to catch more and more attention [32-34]. We speculate that damaged cells could be rescued if necroptosis can be intervened at an early stage, and it will also help us find a better strategy for rational interventional therapy in the future.

Chinese herb has a wealth of resources from natural materials with lower side effects, more economical and other advantages, etc. However, it also has the disadvantages such as its complicated composition which cannot be identified easily. Timosaponin B-II is a monomer which is extracted from Chinese herb rhizomaanemarrhenae, it has multiple pharmacological effects, including antiinflammatory [21,35], anti-diabetic [36], anti-oxidative stress [23,26,27], anti-senile dementia [37], learning ability or memory improvement [21] and neuroprotection [27] or anti-apoptosis effect in human umbilical vein endothelial cells [38], etc. Our MTT assay results showed that viability of RGC-5 in model group $\left(\mathrm{H}_{2} \mathrm{O}_{2}\right.$ treatment) was significantly decreased, while RGC- 5 was pre-incubated by Timosaponin B-II $(1 \mu \mathrm{M}$, $10 \mu \mathrm{M}$ and $100 \mu \mathrm{M}$ groups) for $24 \mathrm{hrs}$, RGC-5 proliferation increased gradually in a dose-dependent manner. The RGC-5 proliferation of $100 \mu \mathrm{M}$ treatment group reached a peak, but it significantly decreased in 1000 $\mu \mathrm{M}$ treatment group. The morphological results suggested that the number of RGC-5 decreased remarkably in model group, the survival of cells tends to be similar as MTT when pretreated with Timosaponin B-II. Taken all together, it indicated that Timosaponin B-II played a protective role on $\mathrm{RGC}-5$ in $\mathrm{H}_{2} \mathrm{O}_{2}$-induced damage under a certain concentration. In addition, our results in flow cytometry showed that the number of RGC-5 cell necrosis significantly reduced in $100 \mu \mathrm{M}$ Timosaponin B-II pretreated group, which suggested that Timosaponin B-II may be partly involved in inhibiting RGC-5 necroptosis under $\mathrm{H}_{2} \mathrm{O}_{2}$ exposed conditions. Moreover, our results on oxidation products measurement also showed that Timosaponin B-II could significantly decrease the accumulation of MDA in RGC-5 in certain range of concentrations. Furthermore, we had observed that TNF- $\alpha$ was also inhibited in Timosaponin B-II pretreatment group. Considering one of the most important pathways in necroptosis (TNF- $\alpha$ induced necroptosis pathway initiate-----necroptosis related molecular modulation----ROS accumulation------cell necrosis [39,40]), we speculated that Timosaponin B-II might inhibit the RGC-5 necroptosis by reducing oxidation products and TNF- $\alpha$ level.

Finally, it is worthy of noting that our experiments revealed the following two questions. Firstly, although Timosaponin B-II can reduce necroptosis by resisting oxidative stress and reduce pro-inflammatory molecule, but it is impossible to recover to normal level, which indicates its limited function as monomer herbal extraction, it also indirectly supports the compatibility usage of Chinese herbal drugs. Secondly, our results showed that higher concentrations of Timosaponin B-II (e.g. $1000 \mu \mathrm{M})$ could be toxic. Frank's research showed Timosaponin B-II and Timosaponin A-III have the similar structure (such as steroid), but Timosaponin B-II presents one more glycosyl [41]. Timosaponin B-II has the trend to convert into Timosaponin A-III. However higher concentrations of Timosaponin A-III has been regarded as highly cytotoxic [41-43] and could cause cell death instead of protective effect. Therefore, we would consider discarding this concentration $(1000 \mu \mathrm{M})$ in future studies. Until now, the molecule of regulation mechanism for cellular necroptosis upon injury was concerned, including receptor interacting proteins (RIPs) $[8,10,12,13]$, calpains [14,44], CDGSH iron-sulfur domain-containing protein 1 (CISD1) [45] or ubiquitin C-terminal hydrolase (UCH-L1) [46], etc. Therefore, whether the possible pathway of Timosaponin B-II neuro-protection may mediate by these molecules mentioned above needs further investigation.

\section{Conclusion}

Timosaponin B-II with limited concentrations can partially protect RGC-5 from $\mathrm{H}_{2} \mathrm{O}_{2}$ induced-necroptosis, which may related to TNF- $\alpha$ and ROS accumulation inhibition.

\section{Competing interests}

The authors declare that they have no competing interests.

\section{Authors' contributions}

LS, J-FH and KX designed the experiment. S-HJ, LS and WD performed the experiment. S-HJ, LS and R-FM drafted the manuscript. SC analyzed the data. $K X$ revised the manuscript and participated in paper modification. $L-X X$ revised the manuscript for English writing. All authors participated in critical revision of the manuscript and approved the final manuscript.

\section{Acknowledgements}

This work is supported by National Natural Science Foundation of China (\#81371011), Wu Jie-Ping Medical Foundation of the Minister of Health of China (320.6750.14118), Natural Science Foundation of Hunan Province (\#2015JJ2187) and Young Teachers Training Program of Normal University of Hunan Province to KX. We are grateful for the provision of Timosaponin B-II from Professor Wan-Sheng Chen in Department of Pharmacology, School of Pharmacology, Second Military Medical University, Shanghai, China.

\section{Author details}

${ }^{1}$ Department of Anatomy and Neurobiology, School of Basic Medical Science, Central South University, Changsha, Hunan 410013, China. ${ }^{2}$ Department of Biochemistry and Molecular Biology, Peking University Health Science Center, Beijing 100191, China. ${ }^{3}$ Xiangya School of Medicine, Central South University, Changsha, Hunan 410013, China. 
Received: 22 August 2014 Accepted: 26 November 2014

Published: 2 December 2014

\section{References}

1. Wu W, Liu P, Li J: Necroptosis: an emerging form of programmed cell death. Crit Rev Oncol Hematol 2012, 82(3):249-258.

2. Han J, Zhong CQ, Zhang DW: Programmed necrosis: backup to and competitor with apoptosis in the immune system. Nat Immunol 2011, 12(12):1143-1149.

3. Bonnet MC, Preukschat D, Welz PS, van Loo G, Ermolaeva MA, Bloch W, Haase I, Pasparakis M: The adaptor protein FADD protects epidermal keratinocytes from necroptosis in vivo and prevents skin inflammation. Immunity 2011, 35(4):572-582.

4. Song KJ, Jang YS, Lee YA, Kim KA, Lee SK, Shin MH: Reactive oxygen species-dependent necroptosis in Jurkat $\mathrm{T}$ cells induced by pathogenic free-living Naegleria fowleri. Parasite Immunol 2011, 33(7):390-400.

5. Wu YT, Tan HL, Huang Q, Sun XJ, Zhu X, Shen HM: ZVAD-induced necroptosis in $L 929$ cells depends on autocrine production of TNFalpha mediated by the PKC-MAPKs-AP-1 pathway. Cell Death Differ 2011, 18(1):26-37.

6. Vanlangenakker $\mathrm{N}$, Bertrand MJ, Bogaert $\mathrm{P}$, Vandenabeele $\mathrm{P}$, Vanden Berghe $\mathrm{T}$ : TNF-induced necroptosis in L929 cells is tightly regulated by multiple TNFR1 complex I and II members. Cell Death Dis 2011, 2:e230.

7. Jouan-Lanhouet S, Arshad MI, Piquet-Pellorce C, Martin-Chouly C, Le Moigne-Muller G, Van Herreweghe F, Takahashi N, Sergent O, LagadicGossmann D, Vandenabeele P, Samson M, Dimanche-Boitrel MT: TRAIL induces necroptosis involving RIPK1/RIPK3-dependent PARP-1 activation. Cell Death Differ 2012, 19(12):2003-2014.

8. Vieira M, Fernandes J, Carreto L, Anuncibay-Soto B, Santos M, Han J, Fernandez-Lopez A, Duarte CB, Carvalho AL, Santos AE: Ischemic insults induce necroptotic cell death in hippocampal neurons through the up-regulation of endogenous RIP3. Neurobiol Dis 2014, 68C:26-36.

9. Chen WW, Yu H, Fan HB, Zhang CC, Zhang M, Zhang C, Cheng Y, Kong J, Liu CF, Geng D, Xu X: RIP1 mediates the protection of geldanamycin on neuronal injury induced by oxygen-glucose deprivation combined with zVAD in primary cortical neurons. J Neurochem 2012, 120(1):70-77.

10. Viringipurampeer IA, Shan X, Gregory-Evans K, Zhang JP, Mohammadi Z, Gregory-Evans CY: Rip3 knockdown rescues photoreceptor cell death in blind pde6c zebrafish. Cell Death Differ 2014, 21(5):665-675.

11. Rosenbaum DM, Degterev A, David J, Rosenbaum PS, Roth S, Grotta JC, Cuny GD, Yuan J, Savitz SI: Necroptosis, a novel form of caspaseindependent cell death, contributes to neuronal damage in a retinal ischemia-reperfusion injury model. J Neurosci Res 2010, 88(7):1569-1576.

12. Dvoriantchikova G, Degterev A, Ivanov D: Retinal ganglion cell (RGC) programmed necrosis contributes to ischemia-reperfusion-induced retinal damage. Exp Eye Res 2014, 123C:1-7.

13. Huang JF, Shang L, Zhang MQ, Wang H, Chen D, Tong JB, Huang H, Yan $X X$, Zeng $L P$, Xiong $K$ : Differential neuronal expression of receptor interacting protein 3 in rat retina: involvement in ischemic stress response. BMC Neurosci 2013, 14:16

14. Shang L, Huang J-F, Ding W, Chen S, Xue L-X, Ma R-F, Xiong K: Calpain: a molecule to induce AIF-mediated necroptosis in RGC-5 following elevated hydrostatic pressure. BMC Neurosci 2014, 15(1):63.

15. Daoud A, Song J, Xiao F, Shang J: B-9-3, a novel beta-carboline derivative exhibits anti-cancer activity via induction of apoptosis and inhibition of cell migration in vitro. Eur J Pharmacol 2014, 724:219-230.

16. Choi S, Keys H, Staples RJ, Yuan J, Degterev A, Cuny GD: Optimization of tricyclic Nec-3 necroptosis inhibitors for in vitro liver microsomal stability. Bioorg Med Chem Lett 2012, 22(17):5685-5688.

17. Wang K, Li J, Degterev A, Hsu E, Yuan J, Yuan C: Structure-activity relationship analysis of a novel necroptosis inhibitor, Necrostatin-5. Bioorg Med Chem Lett 2007, 17(5):1455-1465

18. Zheng W, Degterev A, Hsu E, Yuan J, Yuan C: Structure-activity relationship study of a novel necroptosis inhibitor, necrostatin-7. Bioorg Med Chem Lett 2008, 18(18):4932-4935.

19. Wu Z, Li Y, Cai Y, Yuan J, Yuan C: A novel necroptosis inhibitornecrostatin-21 and its SAR study. Bioorg Med Chem Lett 2013, 23(17):4903-4906.

20. Xing J, Yi-fan F: Advances in studies on saponins in Anemarrhena asphodeloides. Chinese Tradit Herbal Drugs 2010, 41(4):supl12-15.
21. Li TJ, Qiu Y, Yang PY, Rui YC, Chen WS: Timosaponin B-II improves memory and learning dysfunction induced by cerebral ischemia in rats. Neurosci Lett 2007, 421(2):147-151.

22. Kim JY, Shin JS, Ryu JH, Kim SY, Cho YW, Choi JH, Lee KT: Anti-inflammatory effect of anemarsaponin B isolated from the rhizomes of Anemarrhena asphodeloides in LPS-induced RAW 264.7 macrophages is mediated by negative regulation of the nuclear factor-kappaB and p38 pathways. Food Chem Toxicol 2009, 47(7):1610-1617.

23. Zhang J, Zhang M, Sugahara K, Sagara Y, Meng Z, Xu S, Kodama H: Effect of steroidal saponins of Anemarrhenae rhizoma on superoxide generation in human neutrophils. Biochem Biophys Res Commun 1999, 259(3):636-639.

24. Kaname N, Zhang J, Meng Z, Xu S, Sugahara K, Doi Y, Kodama H: Effect of timosaponin E1 and E2 on superoxide generation induced by various stimuli in human neutrophils and on platelet aggregation in human blood. Clin Chim Acta 2000, 295(1-2):129-140.

25. Yun D, Bai-ping M, Yu-wen C, Yu-xian S, Jing-jing Z, Yu-jun S: Protective effects of timosaponin Bll on primary neurons against beta amyloid peptide 25-35. Chinese Pharmacol Bull 2009, 02:244-247.

26. Yun D, Qiuping X, Zhenquan L, Baiping M, Chengqi X, Yang Z: Protective effects of saponin compound from anemarrhena asphodeloides on rat undergone cerebral ischemia/ reperfusion. J Beijing Univ Tradit Chinese Med 2005, 02:33-35.

27. Huang JF, Shang L, Liu P, Zhang MQ, Chen S, Chen D, Fan CL, Wang H, Xiong $\mathrm{K}$ : Timosaponin-BII inhibits the up-regulation of BACE1 induced by ferric chloride in rat retina. BMC Complement Altern Med 2012, 12:189.

28. Li GY, Li T, Fan B, Zheng YC, Ma TH: The D(1) dopamine receptor agonist, SKF83959, attenuates hydrogen peroxide-induced injury in RGC-5 cells involving the extracellular signal-regulated kinase/p38 pathways. Mol Vis 2012, 18:2882-2895.

29. Zhang F, Zhan Q, Gao S, Dong X, Jiang B, Sun L, Tao X, Chen WS: Chemical profile- and pharmacokinetics-based investigation of the synergistic property of platycodonis radix in traditional Chinese medicine formula Shengxian decoction. J Ethnopharmacol 2014, 152(3):497-507.

30. Tsai CH, Yang CW, Wang JY, Tsai YF, Tseng LM, King KL, Chen WS, Chiu JH, Shyr YM: Timosaponin Alll Suppresses Hepatocyte Growth FactorInduced Invasive Activity through Sustained ERK Activation in Breast Cancer MDA-MB-231 Cells. Evid Based Complement Alternat Med 2013, 2013:421051.

31. Laster SM, Wood JG, Gooding LR: Tumor necrosis factor can induce both apoptic and necrotic forms of cell lysis. J Immunol 1988, 141(8):2629-2634.

32. Liang $X$, Chen $Y$, Zhang L, Jiang F, Wang W, Ye Z, Liu S, Yu C, Shi W: Necroptosis, a novel form of caspase-independent cell death, contributes to renal epithelial cell damage in an ATP-depleted renal ischemia model. Mol Med Rep 2014, 10(2):719-724.

33. Lin $\mathrm{W}$, Tongyi $\mathrm{S}$ : Role of $\mathrm{Bax} / \mathrm{Bcl}-2$ family members in green tea polyphenol induced necroptosis of p53-deficient Hep3B cells. Tumour Biol 2014, 35(8):8065-8075.

34. Sawai $\mathrm{H}$ : Characterization of TNF-induced caspase-independent necroptosis. Leuk Res 2014, 38(6):706-713.

35. Lu WQ, Qiu Y, Li TJ, Tao X, Sun LN, Chen WS: Timosaponin B-II inhibits pro-inflammatory cytokine induction by lipopolysaccharide in BV2 cells. Arch Pharm Res 2009, 32(9):1301-1308.

36. Miura T, Ichiki H, Iwamoto N, Kato M, Kubo M, Sasaki H, Okada M, Ishida T, Seino $Y$, Tanigawa K: Antidiabetic activity of the rhizoma of Anemarrhena asphodeloides and active components, mangiferin and its glucoside. Biol Pharm Bull 2001, 24(9):1009-1011.

37. Li Y: The protective effects of TSA after cerebral ischemia in rats. Master Degree. Beijing: Beijing University of Chinese Medicine; 2010.

38. Guo C, Li L, Yang X, Meng Z, Li F, Zhang C, Yang Z: Protective effects of timosaponin B-II on high glucose-induced apoptosis in human umbilical vein endothelial cells. Environ Toxicol Pharmacol 2014, 37(1):37-44.

39. Vandenabeele P, Declercq W, Van Herreweghe F, Vanden Berghe T: The role of the kinases RIP1 and RIP3 in TNF-induced necrosis. Sci Signal 2010, 3(115):re4.

40. Zhang DW, Zheng M, Zhao J, Li YY, Huang Z, Li Z, Han J: Multiple death pathways in TNF-treated fibroblasts: RIP3- and RIP1-dependent and independent routes. Cell Res 2011, 21(2):368-371.

41. King FW, Fong S, Griffin C, Shoemaker M, Staub R, Zhang YL, Cohen I, Shtivelman E: Timosaponin Alll is preferentially cytotoxic to tumor cells 
through inhibition of mTOR and induction of ER stress. PLoS One 2009, 4(9):e7283.

42. Wang $N$, Feng $Y$, Zhu M, Siu FM, Ng KM, Che CM: A novel mechanism of XIAP degradation induced by timosaponin All in hepatocellular carcinoma. Biochim Biophys Acta 2013, 1833(12):2890-2899.

43. Sy LK, Yan SC, Lok CN, Man RY, Che CM: Timosaponin A-III induces autophagy preceding mitochondria-mediated apoptosis in HeLa cancer cells. Cancer Res 2008, 68(24):10229-10237.

44. Cabon L, Galan-Malo P, Bouharrour A, Delavallee L, Brunelle-Navas MN, Lorenzo HK, Gross A, Susin SA: BID regulates AIF-mediated caspaseindependent necroptosis by promoting BAX activation. Cell Death Differ 2012, 19(2):245-256.

45. Shulga N, Pastorino JG: Mitoneet mediates TNFalpha-induced necroptosis promoted by exposure to fructose and ethanol. J Cell Sci 2014, 127(Pt 4):896-907.

46. Sosna J, Voigt S, Mathieu S, Kabelitz D, Trad A, Janssen O, MeyerSchwesinger C, Schutze S, Adam D: The proteases HtrA2/Omi and UCH-L1 regulate TNF-induced necroptosis. Cell Commun Signal 2013, 11:76.

doi:10.1186/1472-6882-14-459

Cite this article as: Jiang et al.: The effect and underlying mechanism of

Timosaponin B-II on RGC-5 necroptosis induced by hydrogen peroxide.

BMC Complementary and Alternative Medicine 2014 14:459.

\section{Submit your next manuscript to BioMed Central and take full advantage of:}

- Convenient online submission

- Thorough peer review

- No space constraints or color figure charges

- Immediate publication on acceptance

- Inclusion in PubMed, CAS, Scopus and Google Scholar

- Research which is freely available for redistribution 